\title{
Reply to 'Comment on "Dependence of shear wave seismoelectrics on soil textures: a numerical study in the vadose zone by F.I. Zyserman, L.B. Monachesi and L. Jouniaux" by Revil, A.’
}

\author{
F.I. Zyserman, ${ }^{1}$ L.B. Monachesi ${ }^{2}$ and L. Jouniaux ${ }^{3}$ \\ ${ }^{1}$ Facultad de Ciencias Astronómicas y Geofisicas, Universidad Nacional de La Plata y CONICET, Paseo del Bosque s/n, B1900FWA La Plata, Argentina. \\ E-mail: zyserman@fcaglp.unlp.edu.ar \\ ${ }^{2}$ Instituto de Investigación en Paleobilogía y Geología, Universidad Nacional de Río Negro y CONICET, Av. Roca 1242, Gral. Roca, Río Negro, Argentina \\ ${ }^{3}$ Institut de Physique du Globe de Strasbourg, EOST, UdS-CNRS UMR 7516, Université de Strasbourg, 5 rue René Descartes, F-67084 Strasbourg, France
}

Accepted 2017 June 13. Received 2017 June 12; in original form 2017 April 4

\begin{abstract}
S UMMAR Y
In this paper we reply to a the comment made by Revil (2017) on our paper (2017, Geophys. $J$. Int., 208), where we describe seismoelectric phenomena in the vadose zone based on the theory of Pride empirically extended for unsaturated conditions. We analyse and answer each one of the enumerated critics, and reaffirm the conclusions of our work. In particular, we prove that using the conductivity model suggested by Revil (2017) does not change our predictions significantly, contrary to what was argued in the comment. Further, in the light of previous and new theoretical and experimental results existing in the literature, we confirm the reasonability of having tested a non-monotonic saturation dependent streaming potential coefficient model besides the monotonic one, and discuss the suitability of assuming a linear relation between the permeability and the excess charge.
\end{abstract}

Key words: Electrical properties; Permeability and porosity; Hydrogeophysics; Numerical approximations and analysis; Wave propagation.

We thank Dr Revil for his comments on our publication, which we answer below. We start by answering his introductory statements; we write in italics when we transcribe text from his Comment.

'... Like in Revil \& Mahardika (2013), they used the van Genuchten's constitutive model to describe the water saturation profile...'

While it is true that we employed the mentioned constitutive model, we were not able to find it in Revil \& Mahardika (2013); the model used by the authors in this work is the one from Brooks \& Corey (1964).

'... ZMJ17 also claim that they have extended Pride's formulation to deal with the modeling of seismoelectric phenomena in partially saturated media. This extension appears, however, to be ad hoc, i.e., not based on any upscaling techniques or fundamental physics. It furthermore contradicts the broad body of published experimental data.'

The sentence 'Correspondingly, we extend Pride's formulation to deal with partially saturated media.', which we wrote in the Summary of our article does not mean that we claim to have developed a new formulation for Pride's theory in unsaturated media, but, as we clearly write in the body of our paper, that we use extended models, previously developed by other authors (Warden et al. 2013). Moreover, we comment below (Answer (3)) that (1) in a previous work
Dr Revil considered the chosen approach to be valid, and (2) laboratory measurements obtained by other authors show good agreement with theoretical results obtained using Pride's seismoelectric theory extended by means of Warden's model.

We continue now by answering the eight reasons enumerated by which we, as Dr Revil poses it, cannot pretend to accurately describe seismoelectric phenomena in the vadose zone with our approach.

$(1,2)$ We think that using Pride's formulation for seismoelectrics is not a drawback at all. This theoretical framework is one of the two most well-known efforts to explain seismic-to-electromagnetic conversions (being the other one Dr Revil's and co-workers'), so we think it is not necessary here to enumerate the large number of works that have been (and continue to be) published using it. However, the interested reader can recourse to recent reviews (Jouniaux \& Ishido 2012; Jouniaux \& Zyserman 2016) to take a glance at most of them.

As we stated in our paper, we are aware that Pride's theory has certain hypotheses that have to be fulfilled for it to be applied; we chose the soil textures, water salinity and other parameters accordingly.

The discussion on the conductivity model is answered in the next point.

(3) Here Dr Revil affirms that we are presenting a new way to deal with the electric conductivity in unsaturated conditions, which 
is poorly fundamented, and incorrect. As we clearly stated in our work, we are not presenting a new model, but using an already known one, introduced by Warden et al. (2013) and used by some of us in a previous work (Zyserman et al. 2015) and other authors as well (Bordes et al. 2015).

On the other hand, in a recent work, Jardani \& Revil (2015) commented about Warden's work as follows: '... In parallel, Warden et al. (2013) extended empirically the equations developed by Pride (1994) to unsaturated media. The extension of the mechanical equations was based on a generalization of the Biot-Gassman theory to the unsaturated conditions. For the electromagnetic problem, the electrical properties such as the dielectric permittivity and the electrical conductivity were expressed as a function of the water saturation.' and further they state: 'These two formulations are valid for the unsaturated case with the second fluid phase being a non-wetting phase, very compressible, and at constant pressure.'

So, Dr Revil not only already knew the model we are using in our work but also considered it valid, whenever the last mentioned conditions are fulfilled. (Note that they are indeed valid in our work.)

To complete our discussion about the electric conductivities, we compare now the conductivity model we used in our work (Zyserman et al. 2017, eq. 12) and Revil's model as given in Revil \& Mahardika (2013); we use therefore for the latter

$$
\begin{aligned}
\sigma= & \sigma^{\prime}+i \sigma^{\prime \prime} \\
= & \frac{1}{F} S_{w}^{\hat{n}} \sigma_{w}+\frac{2}{3} \hat{m}(F-1)\left(\frac{\phi}{1-\phi}\right) S_{w}^{\hat{n}-1} \beta_{(+)}(1-f) \varphi_{W} Q_{V} \\
& -i \frac{2}{3} \hat{m}(F-1)\left(\frac{\phi}{1-\phi}\right) S_{w}^{\hat{n}-1} \beta_{(+)}^{S} f \varphi_{W} Q_{V} .
\end{aligned}
$$

The real part $\sigma^{\prime}$ is called the in-phase conductivity, containing contributions from Archie's law in the first term, and from the surface conductivity in the second term. The imaginary part $\sigma^{\prime \prime}$ is the quadrature conductivity, and accounts for polarization effects. The parameters not already defined in our work are a ionic mobility $\beta_{(+)}$equal to the mobility of the cations in the bulk pore water, the total charge density of the diffuse and Stern layers $Q_{V}$, the fraction of counterions in the Stern layer $f$ and the weight fraction of clay in the soil $\varphi_{W}$. The factor $\beta_{(+)}^{S}$ in the imaginary part is the mobility of the counterions in the Stern layer.

To obtain Fig. 1 we used in eq. (1): $\beta_{(+)}=5.2 \times 10^{-8} \mathrm{~m}^{2} \mathrm{~s}^{-1} \mathrm{~V}^{-1}$, corresponding to $\mathrm{Na}^{+}$at $25^{\circ} \mathrm{C}, \beta_{(+)}^{S}=1.5 \times 10^{-10} \mathrm{~m}^{2} \mathrm{~s}^{-1} \mathrm{~V}^{-1}$ and $f=0.95$ (Revil 2012; Revil \& Mahardika 2013), $Q_{V}=3.15 \times 10^{7} \mathrm{C}$ $\mathrm{m}^{-3}$, corresponding to a shaly sandstone (Waxman \& Smits 1968), and $\varphi_{W}=\gamma_{\text {clay }}$ (Zyserman et al. 2017, table 1). We can observe in Fig. 1, where we depict the real part of the conductivity, that for all soil textures Revil's model yields higher effective conductivities, and that the difference between both predictions is higher for the more clayey soils. This happens because the surface conductivity contributes more significantly in Revil's conductivity model than in Warden's. Below the water table, the conductivity of the sandy clay is 2.1 times higher for Revil's conductivity model than for Warden's conductivity model; all other soil textures have smaller differences.

In order to check if employing Revil's model significantly affects our predictions, we modified our seismoelectric numerical code, considering now the mentioned model, and run our simulations for all soil textures. We display in Fig. 2 the interface response for the electric field, measured below the water table; this figure corresponds to (Zyserman et al. 2017, fig. 12(c)). We choose this figure because it encompasses the most significative results of our paper. What we observe is that the only difference is an amplitude

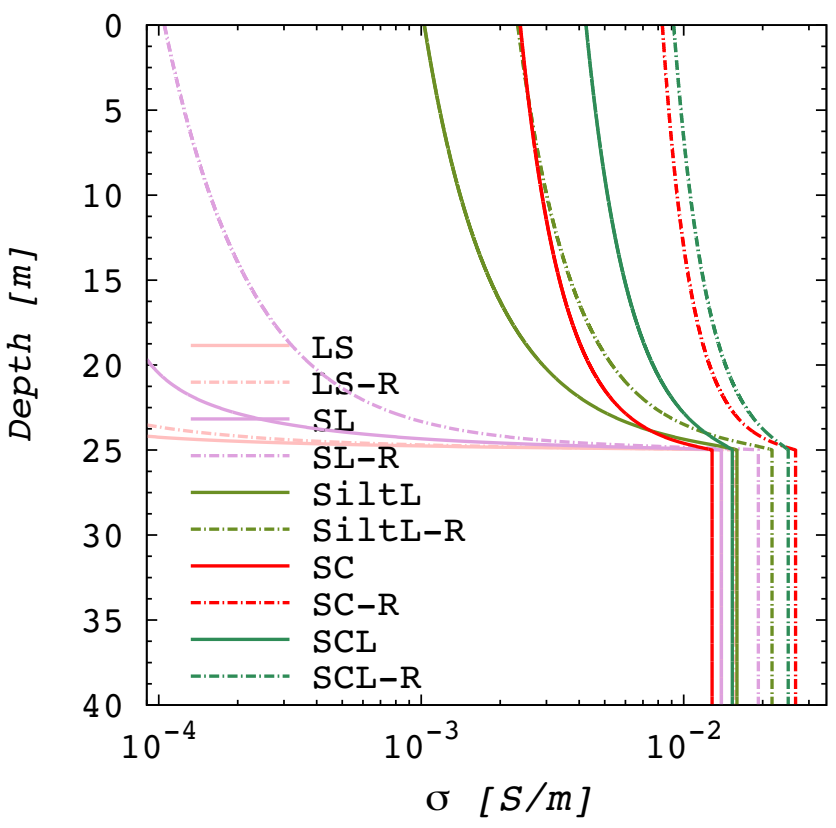

Figure 1. Conductivity profiles (real part), as a function of depth, for the five soil textures analysed in our work (Zyserman et al. 2017), for Warden et al. (2013) and Revil \& Mahardika (2013) conductivity models. LS: loamy sand, SL: sandy loam, SiltL: silt loam, SC: sandy clay, SCL: silty clay loam. The $\mathrm{R}$ following the soil texture name signals the curves corresponding to Revil's model.

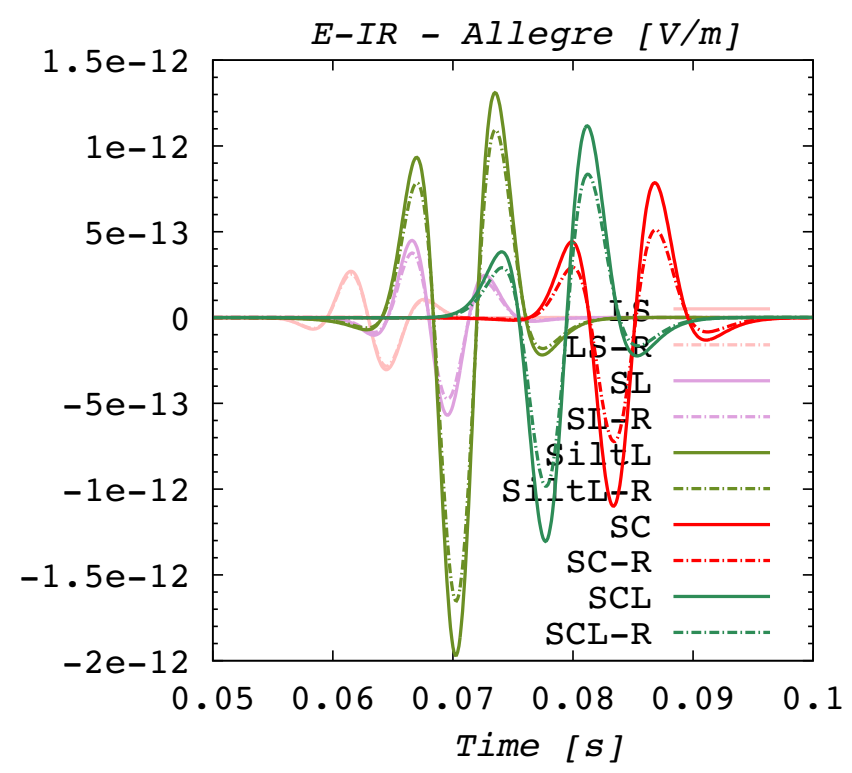

Figure 2. Electric field interface response measured, as in Zyserman et al. (2017, fig. 12c) at $55 \mathrm{~m}$ depth, that is, $30 \mathrm{~m}$ below the water table. Solid lines correspond to the original results, dashed curves to the ones obtained using Revil's model for the electric conductivity $\sigma$.

decay, which is almost negligible for the least clayey soils (loamy sand and sandy loam), and more appreciable for the soils with a higher clay content. But even for the latter, the new amplitudes are fairly close to the original ones.

Therefore, we reaffirm what we stated in our article; in the vadose zone we are working under the hypothesis that Warden et al. (2013) established for their model to be valid, so there is no loss of quality in our predictions because of the used conductivity model. 


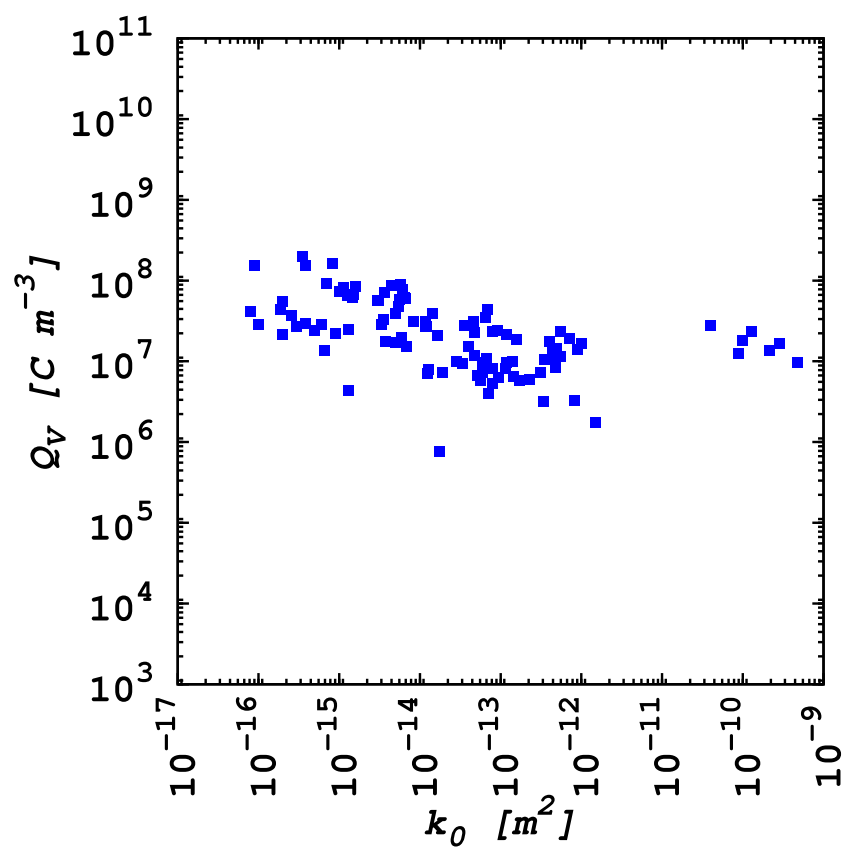

Figure 3. Measured $Q_{V}$ as a function of measured permeability for data from Waxman \& Smits (1968), Waxman \& Thomas (1974) and Vinegar \& Waxman (1984).

(4) We do not agree with the suggested idea that the mere existence of an alternative theory makes it preferable to another one. On the other hand, as we mentioned above, we are aware of the numerous works of Dr Revil and co-workers; we have cited not a few of them in several of our previous papers. Moreover, one of us has already worked with this formulation of seismoelectrics (Monachesi et al. 2015); in this work it is demonstrated that the presence of mesoscopic heterogeneities in fluid-saturated porous rocks can produce measurable seismoelectric signals due to wave-induced fluid flow (WIFF) between regions of differing compressibility.

(5) We thank Dr Revil for providing details on the differences between the volumetric charge densities. However we point out that our results do not depend at all on one or the other volumetric charge densities; within the theoretical frame we employed in our work there is no formula making use of any volumetric charge density, so any confusion we could have with them, did not affect the results in our paper.

We would like to express that even though we may have abruptly stated our questioning about the connection between $\hat{Q}_{V}$ and $k_{0}$ as established in Revil \& Mahardika (2013, Fig. 3) in the introduction of our paper, we still consider that the displayed result is a consequence of the chosen hypothesis, and not verified by independent measurements. In fact, the effective charge density of the diffuse layer that can be dragged by the flow $\hat{Q}_{V}$ is calculated at low frequencies in Revil \& Mahardika (2013) using the eq. (97)

$\hat{Q}_{V}=-\frac{C_{0} \eta_{w} \sigma_{0}}{k_{0}}$

and results are shown in their fig. 3, showing a strong decrease of the effective charge density with increasing permeability $k_{0}$ with a slope of about 0.8 .

Jardani et al. (2007) also stated: 'The measurements of C can be used to determine the values of the charge density of the diffuse layer, and reported values of this charge density calculated for previous measurements published in literature, as the argillaceous samples from Revil et al. (2005).'
But they calculated the values of $\bar{Q}_{V}$ from the eq. (2) instead of calculating $\hat{Q}_{V}$. Moreover we point out here that Jardani et al. (2007) used values of the streaming coefficient measured on five samples by Revil et al. (2005), with permeability values still from Revil et al. (2005), but that were not measured on these samples but taken from the literature. Note also that Linde et al. (2007) used the eq. (2), but to calculate $Q_{V}$, not $\hat{Q}_{V}$, neither $\bar{Q}_{V}$.

On the other hand, as we know that the streaming coefficient $C_{0}$ is inversely proportional to the fluid conductivity $\sigma_{w}$

$C_{0}=\frac{\epsilon \zeta}{\eta_{w} \sigma_{w}}$

and that $\sigma_{0}$ is

$\sigma_{0}=\frac{\sigma_{w}}{F}+\sigma_{s}$

it leads to the following equation:

$\hat{Q}_{V}=-\frac{\epsilon \zeta}{F k_{0}}$,

assuming the surface conductivity $\sigma_{s}$ is neglected, with $F$ the formation factor. So it is not surprising that this $\hat{Q}_{V}$ does not depend on the fluid conductivity as mentioned by Jardani et al. (2007): 'We observe that for a variety of rocks and ionic strengths of the pore water $\hat{Q}_{V}$ depends mainly on the permeability of the porous rocks.'

The values of the different parameters $\epsilon, \zeta, \eta$ and $F$ are not varying in a very large range compared to the permeability which can vary of about 12 orders of magnitude. Therefore using eq. (2) to calculate $\hat{Q}_{V}$ leads to the conclusion that $\hat{Q}_{V}$ is roughly inversely proportional to the permeability. This is a consequence of the hypothesis used for the calculation of $\hat{Q}_{V}$, this is not a demonstration. Taking into account the surface conductivity in the value of $\sigma_{0}$, leads to a relation that may slightly differ from the exact inverse proportionality to the permeability.

It would have been necessary to calculate $\hat{Q}_{V}$ from CEC measurements to have independent measurements of $\hat{Q}_{V}$ and $k_{0}$ to be able to know if there is some relation between $\hat{Q}_{V}$ and $k_{0}$. The total charge density of the diffuse and Stern layer $Q_{V}$ can be deduced from CEC measurements as performed by Waxman \& Smits (1968), Waxman \& Thomas (1974) and Vinegar \& Waxman (1984). $Q_{V}$ is usually determined from the ratio of the cation exchange capacity per unit pore volume of rock, expressed in meq $\mathrm{ml}^{-1}$, with 1 meq $\mathrm{ml}^{-1}=96.32 \times 10^{6} \mathrm{C} \mathrm{m}^{-3}$ (Greve et al. 2013). In Fig. 3, we show the data tabulated in the just mentioned references of measured $Q_{V}$, roughly between $6 \times 10^{6}$ and $10^{8} \mathrm{C} \mathrm{m}^{-3}$ for a permeability range from $10^{-16}$ to $10^{-9} \mathrm{~m}^{2}$.

When the pores are small we can expect $\hat{Q}_{V}=\bar{Q}_{V}$, as recalled by Dr Revil. In Revil et al. (2005) the excess charge density of the diffuse layer $\bar{Q}_{V}$ is related to the total charge density of the diffuse and Stern layers per unit volume $Q_{V}$ as $\bar{Q}_{V}=(1-f) Q_{V}$, with $f=0.98$, and $f$ values from 0.98 to 0.85 in Revil \& Mahardika (2013).

From the independent measurements of $Q_{V}$ and $k_{0}$ in Fig. 3 it is not possible to deduce a linear relation between them with a slope near one, the values of $Q_{V}$ varying about one or two orders of magnitude while the permeability is varying about eight orders of magnitude. Therefore we suggest, when using a model including some values of $\hat{Q}_{V}$ and $Q_{V}$ to choose a value of $Q_{V}$ coherent with the measurements of $Q_{V}$ performed independently.

Note that Jougnot et al. (2012) proposed an alternative way to calculate the effective charge density, modelling a bundle of capillaries. The effective charge density is calculated as a function of the water saturation, using two approaches: the relative permeability 
function, and the capillary size distribution, to derive the size of the capillaries that drains the flow at a given saturation. This size is permeability dependent, and the results show that the predicted effective excess charge at saturation is decreasing with increasing permeability with a slope of about 0.8 . It would be interesting to know if some parameters of the model show some sensibility to the value of the slope in this relationship.

(6) In our work we wanted to test different possible scenarios, therefore we chose two 'saturation functions' $\mathcal{C}\left(S_{w}\right)$ previously reported in the literature, namely a monotonic one and a nonmonotonic one. In this work we are not choosing between both models, but describing what we observe when employing them.

However, we would like to point out that Allègre et al. (2010) did not try to duplicate experiments from Linde et al. (2007). Linde et al. (2007) measured the self-potential during a drainage experiment, but they did not measure the water content of the sand during the drainage, and could not show any streaming potential coefficient as a function of water saturation, as performed by Allègre et al. (2010). Further analysis of their raw data shows that they investigated only a range of water-saturation between 0.85 to full saturation (Jouniaux et al. 2016). Moreover they calculated $Q_{V}$ from eq. (2). Note that both experiments in Allègre et al. (2010), and modelled by Allègre et al. (2012), showed a non-monotonous behaviour of the streaming potential coefficient (Fig. 4), and are the only observation, to our knowledge, of continuous records of the streaming potential coefficient (SPC) during drainages, with also concomitant pressure and water content measurements.

The non-monotonous behaviour of the streaming potential coefficient, as we used, is in agreement with several observations, including some of Dr A. Revil, once the SPC value measured at saturation is properly included, as shown in Fig. 5. The key point here is: when modelling the measurements, if we use the hypothesis that the maximum value of the streaming potential is encountered at full saturation, then the result is that the model is monotonous as a function of the water saturation. If we do not use this a-priori, then we can model a non-monotonous behaviour of the streaming potential coefficient. One physical reason is the existence of the water/air interface which is also charged, as the interface of rock/water, with a zeta potential of about $-20 \mathrm{mV}$ (Allègre et al. 2015). And the evolution of this interface is non monotonous with the water saturation during a drainage (Culligan et al. 2004; Allègre et al. 2015).

The underlying physics of a non-monotonous behaviour of the SPC is related to water/air interfaces as shown by the results of lattice Boltzmann numerical simulations (Fiorentino et al. 2017). Whether the water/air interfaces progresses as an air flow parallel to the channel, or as a flow with entrapped bubbles, or as flowing bubbles, the results predict a non-monotonous behaviour of the SPC with the water saturation (Figs 6 and 7). The main contribution to the SPC comes from the charged water/air interface, and not from the rock/water interface, assuming the same zeta potential for both interfaces. Two competing effects are involved: the decrease of the fluid velocity with decreasing water saturation, and the increase of the charge density and the surface area of the water/air interface with decreasing water saturation. A non-monotonous behaviour of the SPC also appears without any increase of the surface area of the water/air interface with decreasing water saturation.

We also want to mention that Bordes et al. (2015) used the nonmonotonic saturation function proposed by Jackson (2010) for the electrokinetic coefficient in unsaturated conditions, along with the two monotonic ones proposed by Guichet et al. (2003) and Revil et al. (2007). They observed that 'The comparison of data with the
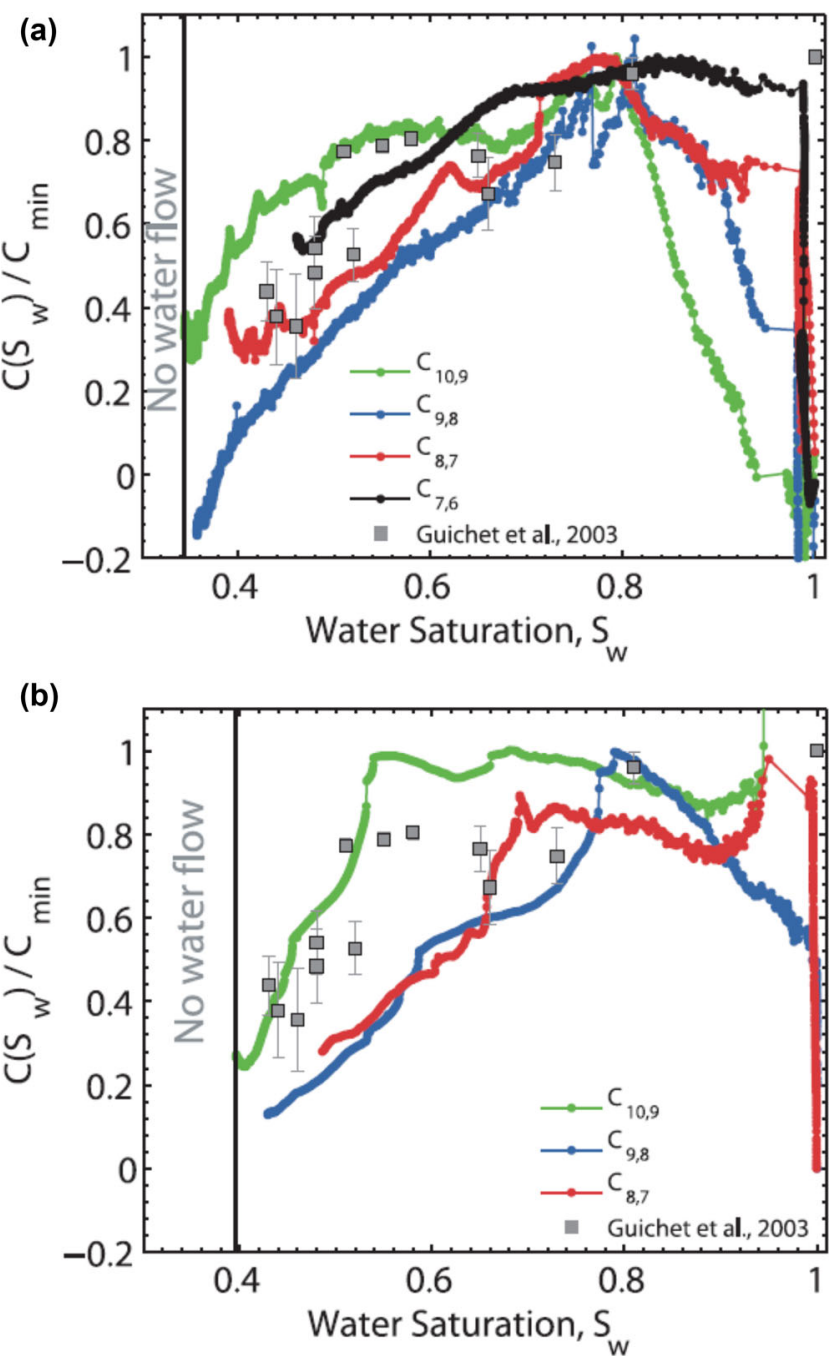

Figure 4. Relative SP coefficients for experiment \#1 and experiment \#2. Water conductivity is $0.01 \mathrm{~S} \mathrm{~m}^{-1}$ for Exp \#1 and $7 \times 10^{-3} \mathrm{~S} \mathrm{~m}^{-1}$ for Exp \#2. From Allègre et al. (2010).

theory led to the conclusion that the trend and the order of magnitude of the recorded experimental transfer functions is recovered by the theoretical prediction when using the Jackson (2010) model for the saturation dependence of electrokinetic coefficient.' This shows that other authors found experimental evidence of a non-monotonic behaviour of the electrokinetic coefficient at partial saturation, and also that they were able to explain laboratory measurements with the same seismoelectric theory we used in Zyserman et al. (2017), that is, Warden et al.'s (2013) extension of Pride's theory to partial saturation.

Finally, we point out that numerical simulations performed by Zhang et al. (2014) suggested that the SPC exhibits a hysteresis between drainage and imbibition and that it can vary nonmonotonically with saturation.

Turning now the reader's attention to the electrode drift, we would like to recall that Allègre et al. (2010) used non-polarizable electrodes and checked the stability of their electrodes over a period of $100 \mathrm{hr}$. The results are described in Allègre et al. (2010): the electrodes showed remarkable stability. At the end of the drainage experiments the electric potential is not the same as the one at the beginning of the experiment: this is not a drift. This is because the sand is water saturated at the beginning of the drainage, and is 


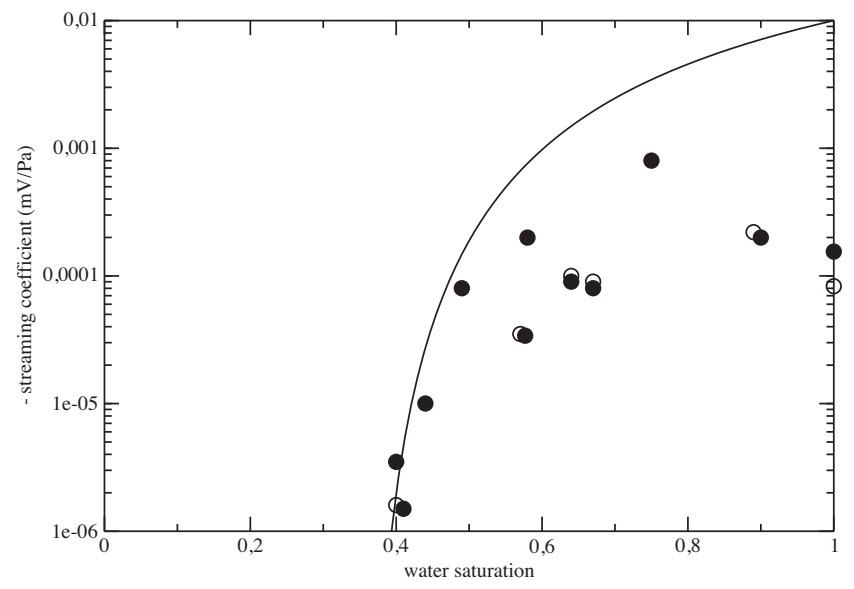

Figure 5. Streaming potential coefficient measured for samples E3 (black circles) and E39 (empty circles) from Revil et al. (2007, fig. 7b) including measurements at full saturation (=1) not reported by Revil et al. (2007) and shown in Revil \& Cerepi (2004, fig. 3) on same samples with the same water conductivity $0.93 \mathrm{~S} \mathrm{~m}^{-1}$. The model from Revil et al. (2007) (continuous line) with $n=2.7 ; S_{w}^{r}=0.36 ; \lambda=0.87$, eq. 112 and 113 calculated with the value at saturation extrapolated from the values obtained at various saturations to $10^{-2} \mathrm{mV} \mathrm{Pa}^{-1}$, which is two orders of magnitude above the measured values. From Allègre et al. (2011).

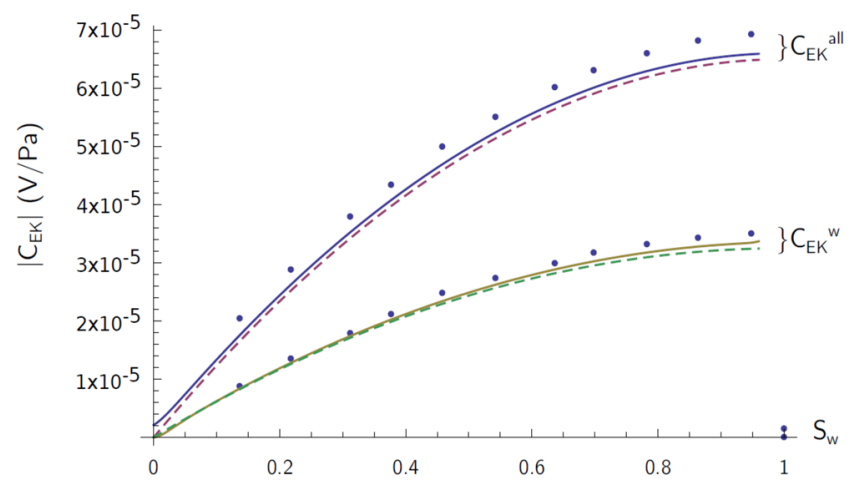

Figure 6. Streaming potential coefficient simulated in a capillary channel with an increasing air corridor in the middle of the channel when the water saturation $S_{w}$ decreases (after Fiorentino et al. (2017)). The streaming potential coefficient is increasing with water saturation, linked to increasing fluid velocity, up to full water saturation where the SPC decreases, linked to the fact that the interface water/air does not exist anymore.

partially saturated at the end. This difference has a physical meaning. In any way these potentials have to be corrected to be the initial value because it is part of the useful signal. The initial value is recorded when water is filled again in the sand. This can be checked for the dipole 2,1 which remained in the fully saturated part. The raw SP data should not be corrected for a drift if the electrodes are stable in saturated medium. Modelling the raw data available in the literature without this a priori final potentials leads to different behaviours of the SPC as a function of water saturation (Jouniaux et al. 2016).

Allègre et al. (2014) proposed continuous self-potential measurements performed during drainage and imbibition cycles. After demonstrating that electrodes were extremely stable over time, especially at very low water saturation, they concluded that none of the existing SPC models could correctly describe their observations. A semi-empirical expression addressing the drainage/imbibition cycle dynamics was used to model the SP measurements. The flow dynamics and the behaviour of water/air interfaces were argued to be

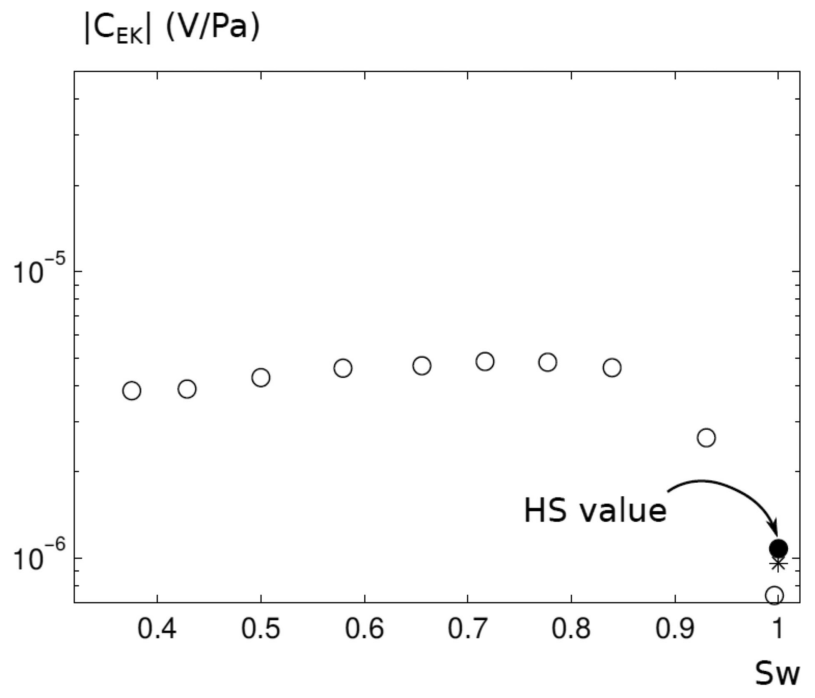

Figure 7. Streaming potential coefficient simulated in a capillary channel with an increasing entrapped bubbles on the wall of the channel for a decreasing water saturation (after Fiorentino et al. (2017)). The streaming potential coefficient shows non-monotonous behaviour with water saturation, linked to a decreasing of the fluid velocity with decreasing water saturation, and to an increasing charge density and surface area of the water/air interface with decreasing water saturation.

of significant influence on the response of unsaturated SP (Allègre et al. 2015). Moreover Zhang et al. (2014) showed with numerical simulations that non-zero SP could be observed in no flow conditions without the need for the electrodes to be responsible for it.

(7) Note that all our results were obtained for a constant value of the $\zeta$ potential, as Dr Revil suggests in his comments that it should be done.

Here we would like to point out that Pride \& Morgan (1991) made a compilation of zeta potentials deduced on $\mathrm{NaCl} /$ quartz and $\mathrm{KCl}$ /quartz data published in the literature and proposed that the zeta potential depends on the logarithm of the salinity. This formula is often used in the literature. Well before, such observations have been made by Overbeek (1952) and Hunter \& Wright (1971). The decreasing potential zeta as a function of the salinity was explained as the contraction of the diffuse layer with increasing salinity. However, Luong \& Sprik (2014) pointed out that the use of such logarithmic law in the Helmholtz Schmoluchowki equation hardly allows to match the SP coefficients of rocks, and that a constant $\zeta$ could be deduced. Jouniaux \& Ishido (2012) proposed, using the compilation on sands and sandstones of Allègre et al. (2010), that $C=-1.2 \times 10^{-8} / \sigma_{w}$, leading to a constant zeta potential of $-17 \mathrm{mV}$. Some authors also proposed that the potential zeta may depend on the grain size and pore throat size (Glover \& Déry 2010), or on the tortuosity (Lorne et al. 1999). Note that the salinity dependence of permittivity and viscosity must be taken into account in the high salinity domain. A more detailed discussion can be read in Fiorentino et al. (2016).

(8) Although it is usually accepted that Biot's theory does not account for squirt-flow, Quiroga-Goode (2002) demonstrated that by introducing heterogeneities of any geometry, Biot equations naturally reproduce viscous flows in any direction relative to the solid matrix and thus squirt-flows.

Notice however, that the latter are due to the presence of pressure gradients, which do not occur in our work, because we 
model 1-D SH waves; recall that we have $u_{s} \equiv u_{s, x}(z, \omega)$ and $u_{f} \equiv u_{f, x}(z, \omega)$, so the fluid pressure $p_{f}=-\alpha K_{a v} \nabla u_{s}-K_{a v} \nabla u_{f}=$ $-\alpha K_{a v} \frac{\partial u_{s, x}}{\partial x}-K_{a v} \frac{\partial u_{f, x}}{\partial x}=0$ always. Because of the same reason, neither can be present WIFF effects due to the presence of mesoscopic heterogeneities, which have been thoroughly studied in last years by several authors; see among others, Picotti et al. (2007), Müller et al. (2010) and Rubino et al. (2015).

Therefore, there is no loss of accuracy in our results because of not considering squirt-flow, because in the studied context, it simply cannot occur.

On the other hand, modelling anelasticity with viscoelasticity is usual when modelling wave propagation in porous media, either with the nearly constant $Q$ model we used, or with standard linear solids, or with Voigt solids, as described in, for example, Mavko et al. (2009) and Santos \& Gazellino (2016).

Finally, concerning the chosen value for the pressure in Walton's model, we doubt it is incorrect; the obtained shear moduli values yield seismic velocities in the range $300-390 \mathrm{~m} \mathrm{~s}^{-1}$, which are usual for unconsolidated soils (Schön 1996).

\section{CONCLUSIONS}

We reaffirm that the results presented in our work Zyserman et al. (2017) are correct within the limits imposed by using Pride's theory of seismoelectrics and its extension to partial saturation proposed by Warden et al. (2013).

\section{ACKNOWLEDGEMENTS}

FZ acknowledges support from CONICET through grant PIP 112201501-00192. We thank INSU-CNRS and the University of Strasbourg for their support.

\section{REFER ENCES}

Allègre, V., Jouniaux, L., Lehmann, F. \& Sailhac, P., 2010. Streaming Potential dependence on water-content in fontainebleau sand, Geophys. J. Int., 182, 1248-1266.

Allègre, V., Jouniaux, L., Lehmann, F. \& Sailhac, P., 2011. Reply to the comment by A. Revil and N. Linde on: "Streaming potential dependence on water-content in fontainebleau sand" by V. Allègre, L. Jouniaux, F. Lehmann and P. Sailhac, Geophys. J. Int., 186, 115-117.

Allègre, V., Lehmann, F., Ackerer, P., Jouniaux, L. \& Sailhac, P., 2012. Modelling the streaming potential dependence on water content during drainage: 1. A 1D modelling of SP using finite element method, Geophys. J. Int., 189, 285-295.

Allègre, V., Maineult, A., Lehmann, F., Lopes, F. \& Zamora, M., 2014. Selfpotential response to drainage-imbibition cycles, Geophys. J. Int., 197, $1410-1424$

Allègre, V., Jouniaux, L., Lehmann, F., Sailhac, P. \& Toussaint, R., 2015. Influence of water pressure dynamics and fluid flow on the streamingpotential response for unsaturated conditions, Geophys. Prospect., 63, 694-712.

Bordes, C., Sénéchal, P., Barrière, J., Brito, D., Normandin, E. \& Jougnot, D., 2015. Impact of water saturation on seismoelectric transfer functions: a laboratory study of coseismic phenomenon, Geophys. J. Int., 200, $1317-1335$.

Brooks, R.J. \& Corey, A.T., 1964. Hydraulic properties of porous media, Hydrol. Pap., 3, 318-333.

Culligan, K.A., Wildenschild, D., Christensen, B.S.B., Gray, W., Rivers, M.L. \& Tompson, A.F.B., 2004. Interfacial area measurements for unsaturated flow through a porous medium, Water Resour. Res., 40, W12413, doi:10.1029/2004WR003278.
Fiorentino, E., Toussaint, R. \& Jouniaux, L., 2016. Lattice Boltzmann modelling of streaming potentials: variations with salinity in monophasic conditions, Geophys. J. Int., 205, 648-664.

Fiorentino, E., Toussaint, R. \& Jouniaux, L., 2017. Two-phase Lattice Boltzmann modelling of streaming potentials: influence of the gas-water interface on the electrokinetic coupling, Geophys. J. Int., 208(2), 1139-1156.

Glover, P. \& Déry, N., 2010. Streaming potential coupling coefficient of quartz glass bead packs: dependence on grain diameter, pore size, and pore throat radius, Geophysics, 75, F225-F241.

Greve, A., Roshan, H., Kelly, B. \& Acworth, R.I., 2013. Electrical conductivity of partially saturated porous media containing clay: an improved formulation, J. geophys. Res., 118, 3297-3303.

Guichet, X., Jouniaux, L. \& Pozzi, J.-P., 2003. Streaming potential of a sand column in partial saturation conditions, J. geophys. Res., 108(B3), 2141, doi:10.1029/2001JB001517.

Hunter, R. \& Wright, H., 1971. The dependence of electrokinetic potential on concentration of electrolyte, J. Colloid Interface Sci., 37(3), 564-580.

Jackson, M.D., 2010. Multiphase electrokinetic coupling: insights into the impact of fluid and charge distribution at the pore scale from a bundle of capillary tubes model, J. geophys. Res., 115, B07206, doi:10.1029/2009JB007092.

Jardani, A. \& Revil, A., 2015. Seismoelectric couplings in a poroelastic material containing two immiscible fluid phases, Geophys. J. Int., 202(2), 850-870.

Jardani, A., Revil, A., Bolève, A., Dupont, J.-P., Barrash, W. \& Malama, B., 2007. Tomography of the Darcy velocity from self-potential measurements, Geophys. Res. Lett., 34, L24403, doi:10.1029/2007GL031907.

Jougnot, D., Linde, N., Revil, A. \& Doussan, C., 2012. Derivation of soilspecific streaming potential electrical parameters from hydrodynamic characteristics of partially saturated soils, Vadose Zone J., 11(1), 272286.

Jouniaux, L. \& Ishido, T., 2012. Electrokinetics in Earth Sciences: a tutorial, Int. J. Geophys., 2012, doi:10.1155/2012/286107.

Jouniaux, L. \& Zyserman, F., 2016. A review on electrokinetically induced seismo-electrics, electro-seismics, and seismo-magnetics for Earth sciences, Solid Earth, 7, 249-284.

Jouniaux, L., Allègre, V., Toussaint, R. \& Zyserman, F., 2016. Saturation dependence of the streaming potential coefficient, in Seismoelectric Exploration: Theory, Experiments and Applications, eds Grobbe, N., Revil, A., Slob, E. \& Zhu, Z., AGU Book, submitted.

Linde, N., Jougnot, D., Revil, A., Matthäi, S.K., Renard, D. \& Doussan, C., 2007. Streaming current generation in two-phase flow conditions, Geophys. Res. Lett., 34, LO3306, doi:10.1029/2006GL028878.

Lorne, B., Perrier, F. \& Avouac, J.-P., 1999. Streaming potential measurements. 2. relationship between electrical and hydraulic flow patterns from rocks samples during deformations, J. geophys. Res., 104(B8), 17 87917896.

Luong, D. \& Sprik, R., 2014. Examination of a theoretical model of streaming potential coupling coefficient, Int. J. Geophys., 2014, doi:10.1155/2014/471819.

Mavko, G., Mukerji, T. \& Dvorkin, J., 2009. The Rock Physics Handbook: Tools for Seismic Analysis of Porous Media, Cambridge Univ. Press.

Monachesi, L., Rubino, G., Rosas-Carbajal, M., Jougnot, D., Linde, N., Quintal, B. \& Holliger, K., 2015. An analytical study of seismoelectric signals produced by 1D mesoscopic heterogeneities, Geophys. J. Int., 201, 329-342.

Müller, T., Gurevich, B. \& Lebedev, M., 2010. Seismic wave attenuation and dispersion resulting from wave-induced flow in porous rocks - A review, Geophysics, 75, A147-A164.

Overbeek, J.T.G., 1952. Electrochemistry of the double layer, in Colloid Science, Irreversible Systems, pp. 115-193, ed. Kruyt, H.R., Elsevier.

Picotti, S., Carcione, J., Rubino, J. \& Santos, J., 2007. P-wave seismic attenuation by slow-wave diffusion: numerical experiments in partially saturated rocks, Geophysics, 72, N11-N21.

Pride, S., 1994. Governing equations for the coupled electromagnetics and acoustics of porous media, Phys. Rev. B, 50, 15 678-15 695. 
Pride, S. \& Morgan, F.D., 1991. Electrokinetic dissipation induced by seismic waves, Geophysics, 56(7), 914-925.

Quiroga-Goode, G., 2002. Dynamics of Biot squirt-flow, Acoust. Res. Lett. Online, 3, 12-17.

Revil, A., 2012. Spectral induced polarization of shaly sands: influence of the electrical double layer, Water Resour. Res., 48, W02517, doi:10.1029/2011WR011260.

Revil, A., 2017. Comment on "Dependence of shear wave seismoelectrics on soil textures: a numerical study in the vadose zone by F.I. Zyserman, L.B. Monachesi and L. Jouniaux", Geophys. J. Int., 209(2), 1095-1098.

Revil, A. \& Cerepi, A., 2004. Streaming potentials in two-phase flow conditions, Geophys. Res. Lett., 31, L11605, doi:10.1029/2004GL020140.

Revil, A. \& Mahardika, H., 2013. Coupled hydromechanical and electromagnetic disturbances in unsaturated porous materials, Water Resour. Res., 49, 744-766.

Revil, A., Leroy, P. \& Titov, K., 2005. Characterization of transport properties of argillaceous sediments: application to the Callovo-Oxfordian argillite, J. geophys. Res., 105, B06202, doi:10.1029/2004JB003442.

Revil, A., Linde, N., Cerepi, A., Jougnot, D., Matthäi, S. \& Finsterle, S., 2007. Electrokinetic coupling in unsaturated porous media, J. Colloid Interface Sci., 313, 315-327.

Rubino, G., Castromán, G., Monachesi, L., Müller, T., Zyserman, F. \& Holliger, K., 2015. Including poroelastic effects in the linear slip theory, Geophysics, 80(2), A51-A56.
Santos, J.E. \& Gazellino, P.M., 2016. Numerical Simulation in Applied Geophysics, Birkhäuser.

Schön, J., 1996. Physical properties of rocks-fundamentals and principles of petrophysics, in Handbook of Geophysical Exploration, Seismic Exploration, vol. 18, ed. Cubitt, J., Elsevier Science Ltd.

Vinegar, H., Waxman, M. \& August, 1984. Induced polarization of shaly sands, Geophysics, 49(8), 1267-1287.

Warden, S., Garambois, S., Jouniaux, L., Brito, D., Sailhac, P. \& Bordes, C., 2013. Seismoelectric wave propagation numerical modeling in partially saturated materials, Geophys. J. Int., 194, 1498-1513.

Waxman, M. \& Smits, L., 1968. Electrical conductivities in oil-bearing shaly sands, Soc. Pet. Eng., 8(1863-A), 107-122.

Waxman, M. \& Thomas, E., 1974. Electric conductivities in shaly sands I. The relation between hydrocarbon saturation and resistivity index: II. The temperature coefficient of electrical conductivity, J. Pet. Technol., 26(2), 213-225.

Zhang, J., Vinogradov, J. \& Jackson, M.D., 2014. Streaming potential dependence on water saturation during drainage and imbibition. $A G U$ Fall Meeting, Abstract \#H51B-0589.

Zyserman, F., Jouniaux, L., Warden, S. \& Garambois, S., 2015. Borehole seismoelectric logging using a shear-wave source: possible application to $\mathrm{CO}_{2}$ disposal?, Int. J. Greenhouse Gas Control, 33, 82-102.

Zyserman, F., Monachesi, L. \& Jouniaux, L., 2017. Dependence of shear wave seismoelectrics on soil textures: a numerical study in the vadose zone, Geophys. J. Int., 208(2), 918-935. 